\title{
laborhifórico
}

ISSN 2359-6910

https://revistas.ufrj.br/index.php/lh/

ARTIGO

Recebido em 4 de dezembro de 2018

Aprovado em 1 de fevereiro de 2019

\section{Toponímia galega e brasileira. Similitudes e diferenças históricas à luz do conflito linguístico}

Galician and Brazilian toponymy. Historical similarities and differences between in light of linguistic conflict

DOI: https://doi.org/10.24206/lh.v5i1.22642

Guillermo Vidal Fonseca

Licenciado em Filologia Galega (Universidade de Santiago de Compostela), cursando doutorado em Linguística na mesma universidade e atualmente Leitor do Centro de Estudos Galegos da Universidad de Extremadura. O artigo nasce como fruto de um estágio doutoral na Universidade Federal do Rio de Janeiro (2018).

E-mail: gvidalfonseca@unex.es ORCID: https://orcid.org/0000-0003-3494-3405 


\title{
RESUMO
}

Galiza e Brasil constituem duas entidades políticas e sociais bem diferenciadas e afastadas geograficamente, mas com peculiaridades históricas e linguísticas similares: ao já conhecido fato de ter surgido a língua hegemônica falada hoje no Brasil no território do Antigo Reino de Galiza soma-se o fato de que ambas foram submetidas, em maior ou menor grau e com maior ou menor êxito, a um processo de substituição linguística que afetou à(s) língua(s) autóctone(s) de cada uma delas. Através de documentos históricos e presentes, analisamos a toponímia de ambas as entidades, Galiza e Brasil, detendo-nos nas similitudes e nas diferenças sociolinguísticas de ambas provocadas por aquele conflito linguístico.

Palavras chave: Toponímia. História. Conflito Linguístico. Brasil. Galiza.

\begin{abstract}
Galicia and Brazil are two well differentiated political and social entities, which are distant geographical located but with similar historical and linguistic characteristics. On the one hand, we must take into account that the dominant spoken language in Brazil nowadays was born in the ancient Kingdom of Galicia. On the other hand, both entities were subjected -in greater or lesser degree and with more or less success- to a process of linguistic substitution, which influenced their native languages' evolution. In this research, we shall analyze the toponymy of these two areas through the study of historical and current sources, focusing on their sociolinguistic similarities and differences, which were caused by the linguistic conflict.
\end{abstract}

Keywords: Toponymy. History. Linguistic Conflict. Brasil. Galiza. 


\section{Introdução e objetivos}

Apesar de geograficamente ambas as realidades se apresentarem tão afastadas (uma, europeia, e do hemisfério norte e a outra, americana, e do hesmifério sul), histórica, linguística e socialmente, as conexões e vínculos entre Galiza e Brasil são inegáveis embora não fossem tradicionalmente bastante tratados no campo acadêmico. Assim, por exemplo, no que diz respeito às relações sociais, tem-se documentado exaustivamente a forte e assídua emigração galega ao Brasil desde, pelo menos, o século XIX, constituindo isso, ademais, um contraste com respeito às demais zonas do estado espanhol ${ }^{1}$. Como veremos adiante, no âmbito linguístico e com uma perspectiva histórica, a situação não é muito diferente.

Referente ao plano sociopolítico, e apesar de que oficialmente o Brasil seja uma nação soberana e a Galiza uma comunidade autônoma do estado espanhol, podemos encontrar semelhanças históricas nos sucessos e circunstâncias que conduziram aos status oficiais anteriores. O que hoje conhecemos como Brasil foi gradualmente colonizado pelos portugueses desde principios do século XVI, quando ainda não existia o estado-nação moderno e os habitantes do território eram de diferentes tribos indígenas que viviam em comunidade e falavam línguas locais (BENNASSAR; MARIN, 2000, p. 11-32). O caso galego, caracterizado por uma substituição das elites dirigentes locais e uma submissão política a um poder central não galego, mas castelhano, desde finais do século XV (BARREIRO FERNÁNDEZ, 1976, p. 107-125; MARIÑO PAZ, 1998, p. 195-205), guarda certas semelhanças com o caso brasileiro no que se refere à perda de autonomia ou poder político próprio (tribal no Brasil; monárquico, nobiliário e eclesiástico na Galiza) a favor de castas estrangeiras usurpadoras, ainda que poucos autores das distintas ramas humanísticas empregam abertamente a etiqueta “colonização" no caso galego. Assim, por exemplo, Beiras (1972, p. 57-60) refere-se a Galiza como "colonia de interior" sob uma perspectiva socioeconômica; do ponto de vista da sociologia, para Grosfoguel (2018, p. vi), Galiza "has a long history of being a subalternized colonized nation inside the Spanish imperial state"; e, por outra parte, desde a linguística, Rodríguez fala de "país colonizado" (1976, p. 223) e de "proceso colonizador" (1976, p. 225). Seja como for, e mesmo em caso de obviarmos essas contribuições, desde a ótica linguística acadêmica nos parecem inquestionáveis tanto o papel do acontecimento colonial na hegemonia atual do português no Brasil, como a histórica "colonización lingüística" da Galiza ${ }^{2}$ a sua condição de vítima do "imperialismo

\footnotetext{
${ }^{1}$ Veja-se, por exemplo, González Lopo (1998, p. 169-194), Eiras Roel (1991, p. 17-39) ou Silva (2013, p. 199), que cifram em esmagadores $70 \%$ a porcentagem de galegos entre os 700.000 espanhóis emigrados no Brasil entre 1880 e 1970.

${ }^{2}$ Veja-se Rodríguez (1976, p. 225). A expressão inclusive aparece com naturalidade em obras que não versam sobre o tema em questão (veja-se FERREIRO, 1999, p. 281-282).
} 
lingüístico" (MORENO CABRERA, 2016, p. 190-193, 281-304), ou simplesmente a penetração e “imposición” da língua castelhana na Galiza (MARIÑO PAZ, 1998, p. 221).

Assim, essas semelhanças históricas no âmbito sociolinguístico (inerentes a certos episódios políticos), unidas às existentes no âmbito puramente linguístico e que em seguida trataremos, levanos a estudar aspectos da toponímia de ambas as realidades (Brasil e Galiza) tratando de encontrar semelhanças e diferenças e procurando pôr em relação essas e aquelas com os acontecimentos históricos ocorridos nos dois territórios, nomeadamente aqueles que têm a ver com o conflito linguístico que Galiza e Brasil sofreram (e ainda sofrem) e que acabamos de explicar.

\section{O vínculo histórico-linguístico entre Galiza e Brasil}

Há aproximadamente três séculos que os Ilustrados galegos reagiram contra a falsa, mas imperante ideia, na Coroa de Castilha do momento, de que o galego era uma deturpação ou um dialeto da língua castelhana, e que o relacionaram com o português. A este respeito, são interessantes as reflexões do Padre Feixoo no seu Teatro Crítico Universal:

Que la lengua Lusitana, o Gallega se debe considerar dialecto separado de la Latina, y no subdialecto, o corrupción de la Castellana, se prueba, a mi parecer con evidencia, del mayor parentesco que tiene aquélla, que ésta, con la Latina. (...) por lo común las voces Latinas han degenerado menos en la Portuguesa. Esto no pudiera ser, si la lengua Portuguesa fuese corrupción, o subdialecto de la Castellana (1785, p. 321).

O frade inclusive afirma que a galega e a "lusitana" são a mesma língua, precisando que a sua origem é no território galego, com base em alguns feitos históricos que remontam ao século $\mathrm{V}$ em diante. Esta prospecção histórica guarda uma surpreendente similitude com as teses defendidas nos últimos anos pelo sociolinguista brasileiro Marcos Bagno (2011, p. 34-39), que também sobre bases históricas critica o imperialismo linguístico português (nomeadamente o presente em autores e manuais sobre língua), defende a etiqueta galego ao invés de galego-português para se referir à língua medieval e das cantigas, afirma que o português não procede do latim, senão do galego (e esse, à sua vez, do latim) e afirma que "essa língua portuguesa, já com esse nome, é que veio nas caravelas usadas pelo imperialismo português para invadir e conquistar terras noutros continentes", sustentando que o português do Brasil se encontra entre a "família de línguas derivadas do galego" (2011, p. 38). 
Monteagudo e Lagares (2017, p. 12-27) sintetizam muito bem a relação linguística existente entre as línguas faladas hoje na Galiza e no Brasil ${ }^{3}$ :

Haveria três pontos essenciais para estabelecer essa filiação genética entre o galego e o português brasileiro: a) a origem comum do galego e do português, no galego medieval; b) a origem do brasileiro no português; c) as rupturas causadas pelos contatos linguísticos; no caso do galego, pelo contato com o castelhano; e no caso do português brasileiro, pelos contatos com línguas indígenas e africanas (2017, p. 16).

Por último, ao vínculo histórico-linguístico ainda se podem acrescentar as similitudes existentes no nível sociolinguístico, no que se refere à diglosia que sofrem ambas as línguas (o galego por parte do espanhol e o português brasileiro por parte do português lisboeta) e com a situação atual do processo de elaboração do padrão de cada uma (MONTEAGUDO; LAGARES, 2017, p. 13-14). No entanto, esse vínculo histórico de que falamos se resume não só à procedência de uma língua da outra, senão também na filiação comum e em aspectos sociolinguísticos semelhantes que continuam a existir nos nossos dias.

\section{A toponímia galega}

\subsection{História e tratamento bibliográfico}

A Galiza constitui um território no qual foram assentados diferentes povos e grupos humanos há vários milênios ${ }^{4}$. Nórdicos, celtas, romanos, germânicos e mesmo árabes foram deixando a sua pegada na toponímia à medida que se iam fundando assentamentos, vilas e cidades; basta fazer um percurso pelas principais obras que tratam a toponímia galega em sentido amplo para encontrar essa explicação histórica ${ }^{5}$.

Sendo assim, tradicionalmente e além da própria investigação etimológica, semântica ou de outro tipo que podem oferecer os topônimos ${ }^{6}$, os estudos de toponímia galega costumam partir da base de dois axiomas intrínsecos: por um lado, uma antiga história sociopolítica da qual emergem (e que acabamos de ver), e, por outra, a riqueza no tocante à quantidade e variedade. Tanto Santamarina (2002, p. 255) como Boullón Agrelo (2010, p. 31) falam da abundância de topônimos na Galiza, esta última precisando que a sua superfície correspondente a só $6 \%$ do total do estado

\footnotetext{
${ }^{3}$ É necessário mencionar aqui, ademais, a denominada corrente reintegracionista, que defende uma ortografia comum entre galego e o resto de variedades historicamente derivadas dele (incluído o português brasileiro), considerando, pois, que são a mesma língua (veja-se MONTEAGUDO; LAGARES, 2017, p. 19-25).

${ }^{4}$ Veja-se Barreiro Fernández (1976, p. 95-148).

${ }^{5}$ Veja-se Ares Vázquez (2011, Presentación), Cabeza Quiles (2008, Introdución), Santamarina (2002, p. 253-256; 1988, p. 87-88) ou Piel (1979, p. 5-11).

${ }^{6}$ No caso galego, bem detalhados por Boullón Agrelo na sua Toponimia galega. Estado da cuestión (2010, p. 31-57).
} 
espanhol e concentra, não obstante, 35\% dos topônimos do estado. E ambos continuam sinalando uma peculiaridade de que já se vem dando conta desde a "Ilustración" com Padre Sarmiento, passando por Filgueira Valverde no século XX.

Ao nosso entender, a conjugação destes dois axiomas faz com que uma ideia ou palavra associada à toponímia galega se repita ao longo da maioria dos trabalhos: patrimônio. A visão da toponímia galega como um patrimônio histórico, formado paulatinamente e cujos nomes vão aparecendo através de um processo natural e submetido a pouca intervenção, e que permanecem, no geral, inalterados artificialmente com o passar do tempo (a não ser por deturpações, como agora explicamos). Isto se faz muito patente, por exemplo, nos nomes precedentes de possuidores germânicos: são topônimos que permanecem inalterados muitos séculos depois da morte das pessoas que deram origem ao topônimo ${ }^{7}$. E a ideia de patrimônio justifica a sua especial proteção (SANTAMARINA, 2002, p. 253-256), motivo pelo qual abundam também nos estudos toponímicos galegos os trabalhos sobre a quantificação, temporização e alcance da castelhanização ou deturpação da toponímia galega (inerentes à colonização linguística da Galiza analisada na introdução) e sobre a restauração, proteção, estandardização ou normalização dos topónimos ${ }^{8}$.

Com esse panorama, e tendo em conta a nossa vontade de analisar a toponímia à luz do conflito linguístico, analisaremos em seguida, sob essa ótica, a toponímia da comarca galega de Barcala, nomeadamente em termos históricos através do Catastro de Ensenada, para logo fazermos uma confrontação com o caso brasileiro.

\subsection{O Catastro de Ensenada: a toponímia barcalesa}

Como indicamos anteriormente (VIDAL FONSECA, 2016, p. 99-117), o Catastro de Ensenada supõe um documento histórico muito aproveitável para a onomástica na Galiza. Levou-se a cabo com o objetivo de unificar os impostos da época, e foi composto em língua espanhola. Nele, por motivos que tem a ver com o próprio objetivo, mas também com a organização social e com as características geográficas e socioeconômicas galegas, aparecem grande quantidade de nomes de pessoa e de lugar, especialmente de toponímia menor. Assim, selecionamos seis documentos da comarca de Barcala (na época, rural e afastada dos principais agentes castelhanizadores urbanos)

${ }^{7}$ Cf. Piel (1979, p. 7-8).

${ }^{8}$ Veja-se uma relação deles em Boullón Agrelo (2010, p. 36-37). Repare-se em alguns títulos mencionados na nossa própria bibliografía. 
através dos quais, depois da pertinente edição, recolhemos todos os topônimos e microtopônimos úteis para o nosso estudo?.

Figura 1 - Localização da comarca de Barcala na Galiza (concelhos de A Baña e Negreira), da qual recolhemos os dados toponímicos do nosso estudo.

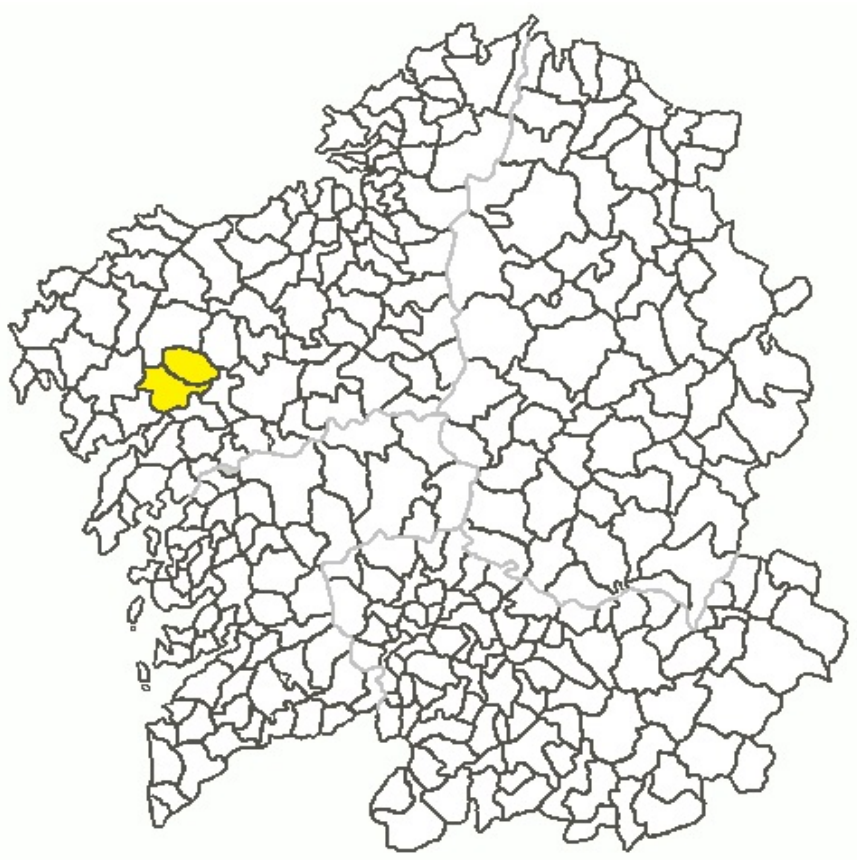

Através dos documentos citados, que concretamente, na comarca em questão, foram elaborados entre os anos 1752 e 1753, recompilamos um total de 322 topônimos e microtopônimos. Desses, um mínimo de 70 estão castelhanizados ou deturpados, total ou parcialmente, de alguma das formas que expõe Santamarina (1988, p. 90-94), o que supõe 21,73\% do total. Eis alguns exemplos:

(1) San Estevan de Lagartones

Peña Rajada

Puertomarín

Villacirío

Huerta da Torre

Fuente Negreira

Cotón de los Castros

\footnotetext{
${ }^{9}$ Os documentos são os seguintes: Interrogatorios das freguesías de Corneira, Logrosa e Bugallido, presentes em Catastro de Ensenada (1751-1753). Disponível em: http://pares.mcu.es/Catastro/servlets/ServletController, consultados em novembro de 2018) e as cópias dos livros Real de Eclesiásticos, Personal de Eclesiásticos e Personal de Legos da freguesia de Corneira, conservados no Arquivo do Reino de Galicia da Coruña. Para os critérios de edição empregados e mais detalhes históricos sobre os documentos e sobre a comarca, veja-se Vidal Fonseca (2016, p. 102104).
} 
Dizemos que estão castelhanizados um mínimo de 70 topônimos porque na microtoponímia, que neste caso não está recolhida nem estandardizada, há muitos nomes de procedência obscura que fazem impossível não só saber se houve castelhanização por parte do escrivão, mas identificar a deturpação no caso de havê-la. Ademais, no caso dos nomes das freguesias, não incluímos como parte do topônimo o padroeiro religioso; caso fizéssemos, o número de vozes alteradas dispararia, posto que aqui a apresentação em espanhol do antropônimo convertido em santo a venerar é sistemática. Eis alguns exemplos:

(2) San Estevan de Lagartones

San Pelayo de Lens

San Juan de Barcala

San Félix de Eirón ${ }^{10}$

A toponímia maior foi identificada praticamente na sua totalidade, não sem dificuldade em certos casos devido à bárbara castelhanização, como: concelhos, paroquias ou lugares da comarca, dos seus arredores ou de outras zonas da Galiza. Assim, identificamos *San Estevan de Lagartones como Santo Estevo de Lagartóns, freguesia do atual concelho da Estrada, em Pontevedra; ou *San Isidro de Postomarco com a paroquia de Santo Isidro de Posmarcos, no concelho da Pobra do Caramiñal ${ }^{11}$. Não ocorre o mesmo com a microtoponímia, já que, até que se faça uma pesquisa da mesma na comarca, não podemos contrastar a continuidade desses lugares e desses nomes quase três séculos depois. A toponímia maior é a mais suscetível de ser castelhanizada, como explica Santamarina (2002, p. 256), já que está mais presente em documentação oficial da época: registros, censos, notarias...; não obstante, na nossa amostra, estão castelhanizados 26,45\% dos microtopónimos (59 em um total de 223), e 11,11\% dos topônimos maiores (11 de 99), isso quer dizer que se o escrivão tem a ocasião propícia de castelhanizar a microtoponímia, ele não hesita ${ }^{12}$. Coisa distinta é que tenha menor possibilidade de fazê-lo pela diferente relevância entre toponímia e microtoponímia. Possivelmente o motivo desta notável diferença de castelhanização entre os topônimos e os microtopônimos na comarca tem a ver com "mecanismos mentais que unhas veces fan percibir ridículas certas castelanizacións [e outras non]" que sinala Santamarina $(1988$, p. 95) ou, sobretudo, com que muitos

\footnotetext{
${ }^{10}$ Exceção: San Tomé de Alvite. Portanto, nos nomes de paróquias com padroeiro só contabilizamos como castelhanizadas *San Mamed de Monte e *San Ciprián de Barcala, cujos nomes estandardizados segundo o Nomenclátor, disponível em: https://www.xunta.gal/nomenclator?, consultado em novembro de 2018, incluem o padroeiro de cada uma: Sanamede de Monte e San Cibrán de Barcala.

${ }^{11}$ Veja-se Nomenclátor, disponível em: https://www.xunta.gal/nomenclator?, consultado em novembro de 2018. Ao contrário, foi impossível identificar com segurança *San Pedro del Puerto, ao que só vemos parecido com a freguesia de San Pedro da Ponte do Porto, no concelho de Camariñas.

${ }^{12}$ Portanto, cremos que a forma em como opera a castelhanização por parte dos escrivãos é muito parecida com o caso dos antropônimos (veja-se VIDAL FONSECA, 2016, p. 110-113).
} 
dos topônimos maiores da zona, especialmente os nomes das paróquias, "non son susceptibles de alteración porque deixaron de ser apelativos ou porque carecen de rasgos fonéticos que os identifiquen como galegos” (1988, p. 90): Portor, Ordoeste, Logrosa, Barcala etc.

$\mathrm{Na}$ maioria dos casos, os livros analisados rondam a citada porcentagem de 21,73\% de toponímia castelhanizada: Interrogatorio de Corneira, 24,66\%; Interrogatorio de Logrosa, 18,75\%; Persoal de Eclesiásticos, 16,66\%; Real de Eclesiásticos, 14,31\%. Rompem a tendência, por motivos bem diferentes, os demais livros: assim, o Persoal de Leigos apresenta uma quantidade tão baixa de nomes (5) que nenhum está castelhanizado; acreditamos, pois, que a mostra é pequena demais para oferecer resultados comparáveis. E, por outra parte, o Interrogatorio de Bugallido, com 35,13\% dos topônimos alterados. Cremos que há que relacionar estes dados com os dos antropônimos nos mesmos documentos: como temos analisado (VIDAL FONSECA, 2016, p. 110-114), o Interrogatorio de Bugallido era o que apresentava mais antropônimos castelhanizados, mesmo em nomes que apareciam na sua forma galega nos outros documentos. Isto reforça a nossa hipótese de que o mais provável é que o escrivão em questão e a sua formação estejam detrás da maior porcentagem de castelhanização onomástica que apresenta o referido documento, incluída a toponímia (2016, p. 113).

Desta forma, o resumo que podemos fazer sobre a história da toponímia galega em termos de castelhanização, ou contato por conflito linguístico, é paralelo à história sociopolítica galega: uma linha temporal composta por uma situação de normalidade galega e de apenas interferência "residual [e] anecdótica"- do espanhol nos topônimos galegos até finais da Idade Média (DOVAL IGLESIAS; HERMO GONZÁLEZ, 2016, p. 193), um posterior processo de castelhanização ativo e significativo durante a Idade Moderna e, finalmente, um processo de estandardização chegado a princípios do século XXI, restaurador das formas galegas e oficializador das mesmas através de certas leis, no caso da toponímia (e que cristalizam no nomeado Nomenclátor), enquanto tal processo continua sem ser terminado no caso da microtoponímia ${ }^{13}$. Mesmo assim, não podemos afirmar que esteja concluída hoje em dia a normalização das formas estandardizadas nem muito menos, posto que continuam existindo resistências às formas regularizadas, sobretudo em casos onde a deturpação logrou tal êxito que tomaram o lugar da forma galega mesmo da fala cotidiana das pessoas galegofalantes, como já apontara Santamarina (1988, p. 95), e também por parte de agentes sociais, empresas ou instituições que se negam a empregar em todos os âmbitos as formas que, segundo a lei, são as oficiais ${ }^{14}$.

\footnotetext{
${ }^{13}$ Veja-se Becker (2014, p. 2453-2464).

${ }^{14}$ Resultam interessantes a este respeito o Diccionario Panhispánico de dudas (REAL ACADEMIA ESPAÑOLA, 2005), que recomenda que em topônimos com mudança de denominação oficial a favor da forma local se deixe de usar o topônimo castelhanizado "solo en aquellos casos en que se ha producido un verdadero cambio de nombre (y no una mera reivindicación de las formas locales de este)” (2005, p. XXIII), ou a Enciclopedia de los Topónimos Españoles (ALBAIGÉS, 1998), que usa a forma deturpada ao lado da genuína argumentando que a necessária normalização das formas próprias só se conseguirá quando todos os cidadãos as conheçam na sua totalidade (onde fica
} 


\section{A toponímia brasileira}

\subsection{História e tratamento bibliográfico}

No ano 1500, quando Pedro Álvares Cabral chega ao que hoje conhecemos como Brasil, habitavam este território entre 1 e 8 milhões de pessoas, segundo os cálculos de distintos especialistas (CUNHA, 2012, p. 16, 17), que, não obstante, coincidem na dificuldade de precisão de cifras mais concretas e fidedignas ${ }^{15}$. Na costa, a densidade populacional seria bem maior que a do interior: Ribeiro (1995, p. 31) dá uma cifra em torno de um milhão de habitantes indígenas (a qual deixaria sem validez as estimações mais baixas para o total do território). Cunha (2012) nos dá uma primeira pista das primeiras relações dos portugueses com o meio que invadiam:

Ao chegarem às costas brasileiras, (...) os portugueses eram o novo Adão. A cada lugar conferiram um nome - atividade propriamente adâmica - e a sucessão de nomes era também a crônica de uma gênese que se confundia com a mesma viagem. A cada lugar, o nome do santo do dia: Todos os Santos, São Sebastião, Monte Pascoal. Antes de se batizarem os gentios, batizou-se a terra encontrada. De certa maneira, dessa forma, o Brasil foi simbolicamente criado. Assim, apenas nomeando-o, se tomou posse dele, como se fora virgem (CUNHA, 2012, p. 8).

Desse jeito, os portugueses chegaram a um continente habitado por tribos indígenas, com uma organização social e econômica completamente diferente da sua (BENNASAR; MARIN, 2000, p. 11-15) e, posto que chegaram pela costa, os seus primeiros contatos foram com os grupos tupi e tupinambá, que habitavam a costa de nordeste a sul (FAUSTO, 2010, p. 68-69). As primeiras relações entre portugueses colonos e indígenas foram amigáveis, em tanto que ambos tiravam proveito da situação (BENNASSAR; MARIN, 2000, p. 66), o que implicou que se produzissem alguns fenômenos linguísticos próprios de duas comunidades com línguas distintas que interagiam: assim, primeiramente o português falado pelos colonos adquiriu progressivamente certas contribuições de léxico tupi (ou do tupinambá, posto que se trataríam de dois dialetos de uma mesma língua $\left.{ }^{16}\right)$ para plantas, animais etc. que não existiam em Portugal, mas também outras de tipo sintático ou fonético, todas elas muito bem detalhadas por Rodrigues (2010, p. 31-36, 44-46) e que supõem um dos primeiros caminhos de divergência entre o português lusitano e o brasileiro. E, por outra parte, nos primeiros anos da colonização, e por motivos estratégicos que não convém nos aprofundarmos aqui, chegavam a essas zonas muito mais homens que mulheres; isso, unido ao

\footnotetext{
a pretendida normalização se continuam a ser usadas num manual as formas conhecidas até esse momento, ou seja, as deturpadas?) (1998, p. 24-25).

${ }^{15}$ Cf. Bennasar; Marin (2000, p. 18).

${ }^{16}$ Veja-se Argolo (2016, p. 11).
} 
estupro e à violência sexual contra as mulheres indígenas como parte da colonização (LACERDA, 2010) acabou gerando crianças de pai português e mãe indígena (portanto, filhos mestiços, também chamados mamelucos) que começaram a falar um tupi ou tupinambá modificados por interferências do português, dando origem a uma espécie de língua híbrida no sudeste brasileiro chamada Língua Geral Paulista ${ }^{17}$. Essa língua finalmente desapareceu por completo a princípios do século XX, devido fundamentalmente à sua proibição e à imposição do português por parte da coroa portuguesa nos finais do século XVIII (GARCÍA, 2013, p. 23-26) e pela chegada de novas camadas de imigrantes portugueses (e de outras nacionalidades) ao longo dos séculos XVIII e XIX (NOLL; DIETRICH, 2010, p. 84); não obstante, a sua importância para o tema que nos ocupa é resumida por Aryon Rodrigues:

Os mamelucos passaram a integrar as expedições ou bandeiras dirigidas mais para o interior de São Paulo, Minas Gerais, Goiás, Mato Grosso, levando consigo o uso das duas línguas, português e língua geral, e atribuindo nomes ora numa, ora na outra aos lugares por onde passavam. Assim é que uma toponímia em língua tupi-guarani, a lingua geral paulista, se fixou em uma ampla área onde povos tupis-guaranis não tinham estado, como Minas Gerais. (...) Como os bandeirantes criavam povoados nos lugares onde se deixavam ficar, a LGP [Língua Geral Paulista] ficou sendo falada nesses povoados em concorrência com a língua portuguesa (...). A LGP, derivada do tupi, tendo-se expandido assim, com a ação dos bandeirantes, pelo interior de São Paulo e Minas Gerais, por Goiás e Mato Grosso e pelo nordeste do Paraná, vigorou na segunda metade do século XVI até a segunda metade do século XIX (RODRIGUES, 2010, p. 37-38).

Isso nos põe em relação com o anteriormente indicado sobre o número de habitantes do território, hoje chamado Brasil, naquela altura. Tendo em conta os seus $8.515 .759,09 \mathrm{~km}^{2}$ (IBGE, 2018) e a estimativa mais otimista de habitantes quando começou a colonização (8 milhões), obtemos uma densidade média aproximada (sem esquecermos que a densidade populacional era maior em áreas costeiras) de $1 \mathrm{hab} . / \mathrm{km}^{2}$, o que implica amplas extensões de território desabitadas no interior. Sendo assim, não resulta muito difícil de explicar a existência das ditas bandeiras em função da procura de matérias primas, recursos econômicos e novos assentamentos humanos.

Ademais, não se deve esquecer os pormenores das circunstâncias linguísticas que rodeiam essas bandeiras ou expedições: a língua geral é levada pelos expedicionários e usada não só como meio de comunicação, mas também como atribuição de nomes dos novos assentamentos. Contudo isso não significa que o português não estivesse presente nas bandeiras, senão que a língua geral é usada "em concorrência” com o português (RODRIGUES, 2010, p. 37). Portanto, o conflito linguístico (sem

\footnotetext{
${ }^{17}$ No noroeste e no leste também surgiram, em circunstâncias diferentes, a Língua Geral Amazônica e a Língua Geral da Bahia, que não trataremos aqui dado que nos centraremos, por questões metodológicas e de espaço, nas amplas regiões sul, centro e nordeste do país. Para mais detalhes sobre ambas, veja-se Rodrigues (1996, p. 6-11; 2010, p. 36-43) ou Argolo (2016, p. 7-52).
} 
dúvida acrescido, visto que chegaram mais imigrantes portugueses nos séculos seguintes) reflete, como poderemos ver com detalhe na nova toponímia, ora indígena, ora portuguesa, ora híbrida. Nesse sentido, podemos dizer que a toponímia brasileira é condicionada por várias línguas que coexistem (mesmo em desigualdade) quando são criados novos assentamentos e não pela deturpação, como é o caso da galega ${ }^{18}$.

Tendo em conta, por outra parte, que a colonização e a sua conseguinte criação de novas cidades e assentamentos desempenhou um papel primordial na história demográfica do Brasil, resulta relativamente comum avistar um termo que sistematicamente aparece na imensa maioria de estudos de toponímia do Brasil $^{19}$, quando menos naquelas zonas ou estados que se viram afetadas pelas referidas expedições desde o século XVI: nomeamento. Isso constitui outra diferença profunda a respeito dos estudos toponímicos galegos. Enquanto os estudiosos dessa disciplina, como víamos, se referem indireta ou diretamente a uma aparição paulatina de nomes que finalmente constitui um acervo patrimonial, os pesquisadores da toponímia brasileira falam de nomeamento, batizado, atribução, nomear, dar nome aos lugares. Se a toponímia brasileira é um ato planificado, consciente, interferido, não arbitrário, mas sim intrínseco a um motor motivacional, então a toponímia englobará também os nomes das ruas ${ }^{20}$, coisa que se opõe diametralmente ao caso galego, onde se considera a toponímia carente ou praticamente carente de intervenção planificada e onde não se costumam incluir os nomes de ruas nos estudos da disciplina (excetuando os casos que um novo nome planificado ou uma extensão urbana fazem desaparecer um topônimo ou microtopônimo patrimonial) precisamente por possuírem essa intervenção criadora arbitrária e não surgirem paulatinamente ao redor de algumas circunstâncias históricas motivacionais. Isso não supõe um problema, pelo contrário, no caso brasileiro, no qual "é muito corriqueiro homenagear pessoas vivas: prefeitos se auto-homenageiam em avenidas e ruas de importância, enquanto deputados e senadores "emprestam" seus nomes para bairros e conjuntos habitacionais" (SEEMANN, 2005, p. 212) de modo semelhante ao que ocorre em muitos casos na toponímia maior, onde com assiduidade encontramos no Brasil cidades com nome do seu fundador ou de uma pessoa homenageada: Lima Duarte, Santos Dumont, Teófilo Otoni ou Conselheiro Lafaiete (Minas Gerais), Luis Eduardo Magalhães (Bahia) etc. O mais parecido que podemos encontrar a isso na toponímia maior galega serão os nomes germânicos ou latinos de

\footnotetext{
${ }^{18} \mathrm{O}$ motivo fundamental desta diferença se deve a que, no caso dos topônimos galegos, uma maioria deles já estaria formada antes de finais da Baixa Idade Media, quando começou o conflito linguístico com o castelhano (SANTAMARINA, 2002, p. 256) e o resto, os que se formariam do século XV até o XVIII, pelo fator geográfico ou de hábitat rural/urbano do conflito linguístico (veja-se MARIÑO PAZ, 1998, p. 195-230, 344-345) deixaria limitadas as opções do castelhano de ser língua dos topônimos mais tardios. Em contraposição, como salienta Santamarina (188, p. 94), estariam muitos nomes de ruas e praças nas cidades que "non coñece[ron] nunca outra forma senón a castelá".

${ }^{19}$ Para mais detalhes sobre os objetivos, as perspectivas e o estado dos estudos da toponímia brasileira, veja-se Carvalhinhos (2008). A autora critica que pelo geral se limitem a listas de nomes com possíveis explicações etimológicas, sem levar em conta os fatores humanos, espaciais, culturais e cronológicos nos quais se situam.

${ }^{20}$ Como exemplos disto, vejam-se os trabalhos de Santos (2016, p. 171-195) ou Velasco; Tavares (2016, p. 15-34).
} 
possuidor (por exemplo, Chave). Contudo, dada a antiguidade e a evolução fonética que sofreram, há tempo que se perdeu, na maioria deles, a noção de pessoa que lhe dá nome. Ademais, sempre surgem do proprietário, da propriedade de um senhorio que com o passar do tempo se vai convertendo em assentamento (PIEL, 1976, p. 7), nunca vem o nome depois desse, como pode ocorrer no Brasil por rebatizados ${ }^{21}$

Outro condicionante que possui a toponímia brasileira e que convém não esquecer é o da anteriormente citada imigração dos séculos XVIII e XIX, nomeadamente (e além da portuguesa) aquela que representa o sequestro e a condução em massa de africanos para a América para se tornarem escravos (VILA DE PRADO, 2017), que longe de só afetar a sobrevivência das línguas gerais, ocasionalmente também deixou a sua pegada em topônimos de certas zonas ${ }^{22}$. Não obstante, não terminam aqui os fatores que influenciam de maneira determinante sobre a construção histórica da toponímia brasileira. Deve-se apontar ainda, em relação aos rebatizados, um significativo período histórico do século XX como é a presidência de Getúlio Vargas (1930-1945) e o ditatorial Estado Novo incluído na mesma (1937-1946). Essa etapa, entre outros traços econômicos, sociais e ideológicos, caracterizou-se por uma intensificação do nacionalismo brasileiro através dos esforços para criar uma cultura brasileira, baseada em princípios geográficos, históricos e culturais que integrariam todas as etnias e os povos do país: as pessoas indígenas, as africanas e as européias fundidas numa identidade comum, a brasileira (BENNASSAR; MARIN, 2000, p. 353-364). Tratava-se, pois, de uma política identitária orgulhosa da mestiçagem (em todas as suas vertentes) e de todas as raízes históricas do país. Isso implicou uma série de consequências no âmbito toponímico, resumidas por Seemann:

As consequências do nacionalismo getuliano se refletiram no ordenamento do território brasileiro. Quanto à nomenclatura dos lugares, foi constatado, entre outras "irregularidades", um "regime de confusão e arbítrio", verificando-se a identidade de denominações no mesmo estado, a extensão exagerada de muitos topônimos oficiais completos de sete e mais palavras e a diversidade de designação entre muitas circunscrições e as respectivas sedes (SEEMANN, 2005, p. 216).

Desse jeito, estabelece-se uma política de intervenção e manipulação da toponímia brasileira, cujo parâmetro será "a preferência pela adoção de nomes indígenas ou relacionados a fatos históricos da região, no caso de substituição de topônimos” (SEEMANN, 2005, p. 216). Citando Pompeu Sobrinho, o próprio Seemann descreve as chaves dessa política de tupinização toponímica:

\footnotetext{
${ }^{21}$ Vejam-se exemplos em Seemann (2005, p. 215).

${ }^{22}$ Veja-se um exemplo de trabalho a respeito em Lima (2012).
} 
Para o fortalecimento deste "espírito nacional", a Comissão seguiu as recomendações federais para "crismar" as vilas e cidades: dava-se preferência aos nomes indígenas que deveriam pertencer à língua dos índios que habitavam a região e "ter significação adequada, ligada a qualquer circunstância local, tal como sabiam fazer excelentemente os ameríndios”. Ademais, os vocábulos novos preferivelmente deveriam ser dissílabas, evitando-se "expressões chocantemente cacofônicas" (SEEMANN, 2005, p. 216-217).

Sendo assim, e como pudemos ver até agora, a história do Brasil possui uma série de elementos que influíram e influem na construção da sua toponímia, tornando-a sofisticada, pelo menos no que concerne ao contato linguístico. Aparecem nela várias línguas simultaneamente, e gozam de um importante papel, as expedições e assentamentos, a proibição de línguas e os renomeamentos. Ademais, ainda que aqui tentamos fazer um esboço geral, o país é demasiado extenso para ter em conta pormenorizadamente todos os fatores de todas as áreas geográficas. Por isso, em seguida faremos um percurso por vários estados brasileiros, excetuando especialmente, como dissemos, as zonas amazônicas onde regem outras características históricas, tratando de observar todas as características até aqui tratadas em cada toponímia e direcionando especial atenção à língua dos topônimos para dar conta dos efetos do contato linguístico. Como nesse caso o estudo toponímico não é próprio, utilizamos diversos autores que trataram de perto a toponímia indígena e o contato de línguas em determinados estados ou regiões de estados brasileiros.

Figura 2 - Estados da República Federativa do Brasil nos quais examinamos algumas de suas toponímias²3.

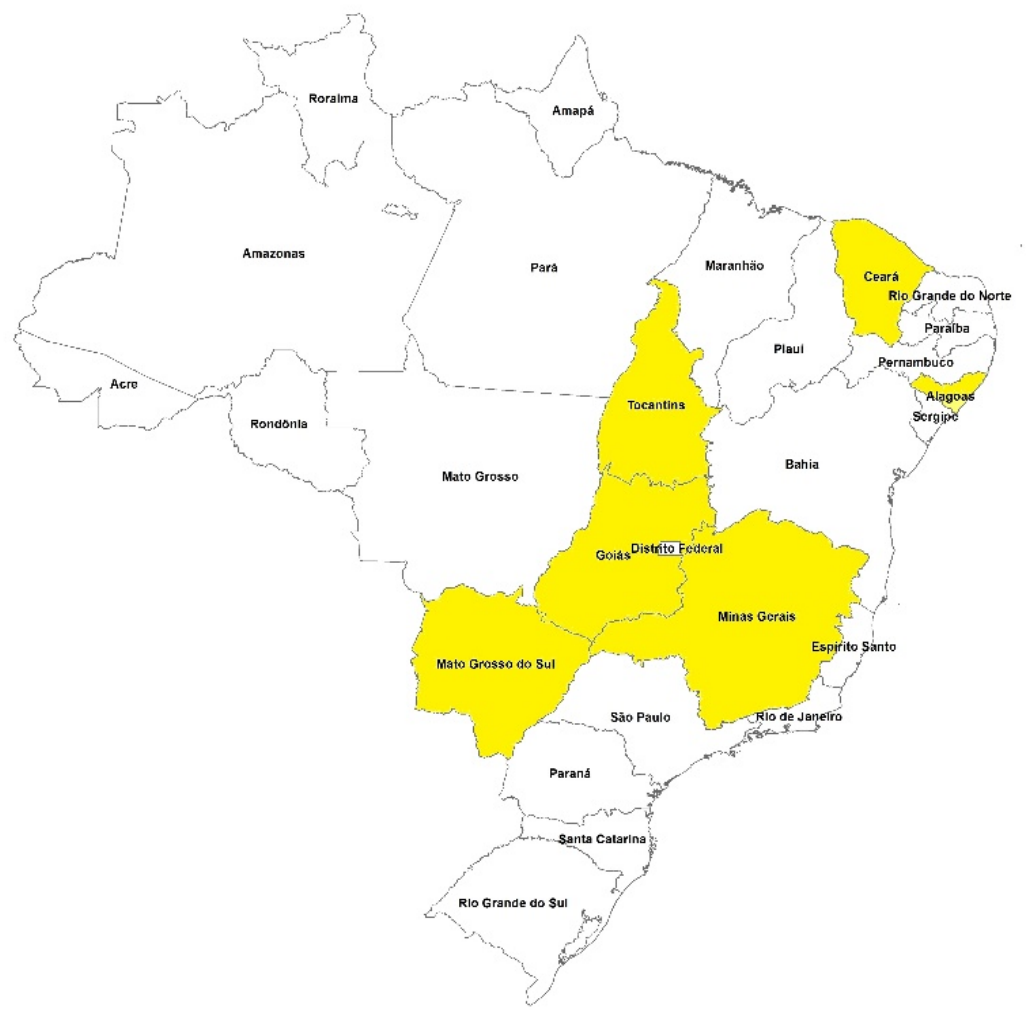

${ }^{23}$ Mapa cortesia de Gustavo Vidal. 


\subsubsection{Minas Gerais}

O estado de Minas Gerais, situado na região sudeste do país, mas sem contato com o litoral, é um dos estados mencionados por Rodrigues (2010, p. 37, 38) como destino dos bandeirantes do século XVI em diante. Em consequência, Pimentel dá-nos uma das chaves iniciais da toponímia mineira:

Se formou a partir de uma etnia diversificada, composta por estratos populacionais diversos, como os ameríndios, (...) os portugueses; os africanos. Por essas razões, a nomenclatura geográfica do território mineiro se apresenta tão heterogênea quanto o seu próprio povo, fato este que se reflete na língua, nos usos e costumes regionais e, consequentemente, na toponímia local (PIMENTEL, 2016, p. 617, 618).

A esse respeito, pois, destacam-se no estado os estudos da pesquisadora Maria Cândida Seabra e de vários outros que, dando continuidade, têm analisado a toponímia de Minas Gerais e nos fornecem dados destacáveis com respeito à questão linguística dos topônimos e ao conflito linguístico implícito. Assim, segundo Seabra (2004), que investigou a região do Carmo ${ }^{24}, 82 \%$ da toponímia dessa zona é de origem portuguesa e só 7,5\% seria indígena, e 2,4\% africana. Os motivos dessa desproporção em favor da língua colonial, segundo a autora, devem-se a que os bandeirantes paulistas, em companhia dos índios, "abriram caminhos, porém poucos se fixaram e, desses, muitos se retiraram da região do Carmo" e que, ademais, "poucos topônimos tiveram em épocas passadas nomes de origem tupi ${ }^{25}$, mudados, posteriormente, para nomes de origem portuguesa" (SEABRA, 2004, p. 308-309). Em proporções semelhantes se desenvolvem as pesquisas de Santos (2012), que investigou a região Central do estado e encontrou em 85,3\% nomes portugueses, apenas 12,5\% indígenas e 2,2\% africanos, ainda que considere uma "lacuna de difícil preenchimento" (SANTOS, 2012, p. 221) elucidar os motivos históricos dessas proporções. Em resumo, pois, quando menos em algumas zonas do estado de Minas Gerais, podemos dizer que o triunfo da língua colonial sobre as indígenas desde o século XVI foi contundente no plano toponímico.

\footnotetext{
${ }^{24}$ Zona situada ao sul da capital mineira, Belo Horizonte, próxima a ela. As subdivisões administrativas dentro de cada estado foram modificadas pelo IBGE em 2017, denominando-se atualmente regiões geográficas intermediárias e, dentro delas, as regiões geográficas imediatas, eliminando a antiga denominação mesorregiões e microrregiões (veja-se A Divisão Regional do Brasil em Regiões Geográficas Imediatas e Regiões Geográficas Intermediárias 2017, 2017). A região do Carmo corresponde, desconhecemos se em parte ou na sua totalidade, à atual região geográfica imediata de Santa Bárbara-Ouro Preto.

${ }^{25}$ A língua geral paulista, por se formar a partir do tupi, é denominada simplesmente como tupi em muitos estudos, mas não se deve confundi-las. Veja-se uma explicação pormenorizada das diferenças entre as duas em Stessuk (2006, p. 96-98).
} 


\subsubsection{Ceará}

Resulta interessante distanciar-nos até uma região do nordeste brasileiro para olhar as diferentes explicações históricas que podem aparecer ao longo do território em função da origem linguística dos topônimos. Nesse senso, Seemann (2005) estudou os topônimos municipais do estado de Ceará e advertiu quase a metade deles como indígenas (aos quais deveria acrescentar os híbridos portuguêstupi, já que só cataloga 25\% como de origem portuguesa). Essa importante diferença com respeito a Minas Gerais deve ser atribuída em muitos casos, como o próprio autor indica (2005, p. 213-214), às políticas tupinizantes da era Getúlio Vargas, que, sem dúvida, tiveram que ser mais intensas no Ceará se comparado com Minas Gerais. Esse seria um exemplo claro de intervencionismo ou rebatizado, e inclusive assim não deixa de mostrar as complexidades do conflito linguístico brasileiro na toponímia.

\subsubsection{Tocantins}

Um caso especialmente chamativo e cheio de condicionantes é o do estado de Tocantins, bem analisado através de Karylleila Andrade e o seu Atlas Toponímico de origem indígena do estado de Tocantins - Projeto Atito (2006). Para começar, é o último dos estados brasileiros, constituído no ano de 1989 logo depois de se separar do estado de Goiás, hoje situado ao seu sul. Ademais, desde essa data, criaram-se 70 novos municípios com os respectivos nomes novos, de modo que estamos falando de nomeamento recente e criação toponímica ad hoc. A seguir, a autora salienta que dos 139 municípios atuais, 71 nomes são de origem tupi, o que representa mais de 50\% dos topônimos; não obstante, antes de 1989, quando na mesma zona havia só 60 municípios, desses, apenas 15 eram de procedência indígena, o que quer dizer que 56 nomes indígenas foram criados desde finais dos anos 80 do século XX. Isto supõe uma espécie de continuidade contemporânea da política Vargas de tupinização da toponímia. Quanto ao resto dos topônimos mais antigos, Andrade relaciona o importante índice de nomes indígenas no estado com as expedições dos bandeirantes, descartando que fossem dados pelos próprios indígenas da zona, o que entra em consonância com os postulados de Rodrigues (2010). Assim, Tocantins constitui um exemplo de como uma língua (a geral paulista), que logo sofreu o imperialismo linguístico do português até desaparecer, foi no seu momento uma língua colonizadora ao dar nome a lugares onde se assentavam expedições chegadas de outros lugares. Ademais, pode-se também concluir que o espírito de apego às línguas indígenas (ou ao tupi) da era Vargas, como elemento histórico e identitário do povo brasileiro, continua vigente até as épocas mais recentes, pois essas são usadas para batizar novos topônimos. 


\subsubsection{Goiás}

Com base em seu estudo Topônimos de origem indígena: O papel do tupi na nomeação dos lugares goianos, Siqueira e David (2014) afirmam que 70 dos 246 municípios do estado têm nome indígena tupi, seja totalmente ou com formação híbrida. Isto representa 28,46\% (sem que especifiquem a procedência dos $71 \%$ restante). Não obstante, e em consonância com o que acontecia em Tocantins, território que anteriormente lhe pertencia, as tribos indígenas de Goiás não eram tupis nem falavam essa língua, como se esforçam por aclarar as autoras: baseando-se no antropólogo Darcy Ribeiro, nomeiam perto de 20 diferentes grupos indígenas que habitavam esta zona em tempos da colonização. Portanto, a presença de nomes tupis na atualidade é atribuída, novamente, às bandeiras cujas línguas, a geral paulista e o português, atuaram como línguas colonizadoras também nesse território. Ainda assim, nem todos os topônimos são dessa época, mas também posteriores, o que leva as autoras a formular a interessante conclusão de que "o tupi desempenha, na tradição brasileira, papel parecido com o latim e o grego antigo nas ciências, isto é, representa uma fonte virtual, um depósito de raízes lexicais produtivo para se formar e até construir topônimos” (SIQUEIRA; DAVID, 2014, p. 130).

\subsubsection{Alagoas}

O estado de Alagoas possui um atrativo nesta pesquisa, pois está situado na costa nordeste brasileira e, portanto, constitui um dos estados onde as tribos tupis estavam instaladas originariamente. Isso quer dizer que é uma das zonas onde os topônimos de origem tupi, que atingem 23 dos 102 municípios do estado (22,55\%) segundo o estudo de Melo (2013), se encontram de jeito mais natural ou, em outras palavras, menos colonial, por efeitos das bandeiras como vimos nas outras zonas. Não obstante, como insinua o próprio autor (2013, p. 177), isso não é impedimento para a aparição de topônimos mais achegados aos nossos dias e que, em paralelo com os outros estados analisados, tomam nomes de base tupi pela tradição a que apontavam Siqueira e David (2014).

\subsubsection{Mato Grosso do Sul}

A fonte que tomamos como base da nossa pesquisa no estado de Mato Grosso do Sul, Velasco e Tavares (2016), conecta-nos de novo com outro dos traços diferenciadores da toponímia brasileira anteriormente mencionados: o estudo dos nomes das ruas das cidades como toponímia, com independência da antiguidade dos mesmos e da sua relação com meio existente antes da presença 
urbana. As autoras reconhecem apenas 7\% de nomes de ruas da cidade de Dourados em idioma indígena, "em geral, do Tupi” (VELASCO; TAVARES, 2016, p. 31); isso produz certo espanto, posto que, como as autoras explicam, os moradores indígenas da zona (ainda presentes na atualidade) são de vários grupos do ramo guarani. Portanto, a conclusão é simples: os topônimos indígenas das ruas de Dourados "não possuem relação com a presença e com os aspectos culturais dos indígenas da região" (2016, p. 31), o que põe de novo, no centro da questão, o tupi, através da língua geral paulista, e o português como línguas de formação atual de topônimos, embora a primeira delas já ter sido extinta.

\section{Conclusões}

Pelo que pudemos expor até aqui, através de um percurso pela história das toponímias galega e brasileira, uma das conclusões mais elementais que podemos tirar é a de que ambas as toponímias possuem mais diferenças que semelhanças, ainda que que possuam um traço fundamental em comum que as vincula: um conflito linguístico, com diferentes características, intensidades e resultados, que influiu de algum jeito na toponímia dos dois territórios e condicionou os seus resultados atuais. No caso galego, o conflito gera-se com a aparição do castelhano através da submissão política à Coroa de Castilha; no caso brasileiro, através de vários fatores: primeiro, a colonização portuguesa e o seu posterior imperialismo linguístico, materializado com a imposição do português no século XVIII; e, ademais, por meio das línguas gerais, híbridos gerados a partir da própria colonização sobre as línguas indígenas locais, que foram dando topônimos em áreas onde existiam outras tribos e outras línguas.

Em relação à temporização, o processo começou antes na Galiza, mas em ambos os casos não chegou a consumar-se posto que continua a existir toponímia indígena tanto no Brasil como, logicamente, galega na Galiza; não obstante, isso é muito matizável no Brasil dado que, enquanto a família tupi vigorou na toponímia graças às bandeiras até hoje, outras línguas indígenas desapareceram ou quase não fica rastro delas nos nomes de lugares de muitas zonas do Brasil.

Sendo assim, as distintas circunstâncias históricas envoltas nos dois casos, incluindo a demografia, o povoamento e as características da ocupação colonial, provocam também a distinta consideração que recebem os topônimos galegos e os brasileiros, centrados no patrimônio a conservar pelos estudiosos dos galegos enquanto os brasileiros falam do nomeamento, do rebatizado e das motivações para os nomes de lugar. Isso está relacionado também com as consequências do conflito linguístico, que provocam dois fenômenos diferentes a um e outro lado do Atlântico: deturpação no caso galego, estendida no tempo e com êxito parcial, e nomeamento intervindo no 
caso brasileiro, através da colonização do território mediante expedições e bandeiras, com continuidade no tempo e com rendibilidade até os nossos dias por meio de decisões políticoadministrativas.

Consequentemente, à toponímia galega se the presume a vontade de conservação, nomeadamente frente aos agentes externos, que se consideram deturpações; isso se faz evidente através de leis e projetos investigadores que culminam na estandardização dos topônimos e nas ânsias de recolhida da microtoponímia, enquanto a toponímia brasileira está mais sujeita à manipulação interna, que não se considera deturpação e que ao longo do tempo se fez habitual, sendo principais exemplos disto a política de tupinização da toponímia da época Vargas (1930-1945) ou a criação ad hoc de novos nomes para novos assentamentos. Assim, se no caso de Galiza o galego nunca deixou de ser a língua tradicional da toponímia ainda que com certas interferências, no Brasil o tupi (através da lingua geral paulista) converteu-se em uma espécie de língua clássica para os topônimos, conseguindo por uma parte conservar um importante legado do mundo indígena pré-colonial, mas acabando simultaneamente com outras muitas ramas e manifestações linguísticas indígenas paralelamente com o português. Curiosamente, e como semelhança, o fato de que a língua colonizadora por excelência do Brasil, o português europeu, tivesse a sua origem no galego, provoca que existam no Brasil estruturas toponímicas muito semelhantes às outras galegas, dada a origem comum das línguas.

Em definitiva, ambas as realidades mostram a inter-relação que mantêm a toponímia e o conflito linguístico, e também o interesse que suscita o estudo da toponímia para a pesquisa histórica do mesmo, assim como a importância de ter em conta a história social da língua, em paralelo com a história, para desenvolver estudos toponímicos de qualidade. Se hoje em dia a Galiza e o Brasil possuem realidades toponímicas com mais diferenças que semelhanças, deve-se, fundamentalmente, à presença nos dois territórios de conflito entre várias línguas ao longo do tempo e em determinadas fases da sua história. E, além de todos estes pormenores, aguardamos, mediante os estudos dos seus nomes de lugar, pôr um degrau a mais na aproximação social, linguística e acadêmica entre o Brasil e a Galiza. 


\section{Referências bibliográficas}

ALBAIGÉS, Josep Maria. Enciclopedia de los Topónimos Españoles.

Barcelona: Enciclopedias Planeta, 1998. ANDRADE, Karylleila dos Santos. Atlas Toponímico de origem indígena do estado de Tocantins - Projeto Atito.

Tese (Doutorado em Linguística), Faculdade de Filosofía, Letras e Ciências Humanas, Universidade de São Paulo, São Paulo, 2006. Disponível em:

http://etnolinguistica.wdfiles.com/loca 1--files/tese\%3Aandrade2006/TESE_KARYLLEILA_SANTO S_ANDRADE.pdf. Acesso em: $20 \mathrm{dez}$. 2018.

ARES VÁZQUEZ, Nicandro. Estudos de toponimia galega. Tomo I. A Coruña: Real Academia Galega, 2011. ARGOLO, Wagner. As línguas gerais na história social-linguística do Brasil. Papia, v. 1, no 26, p. 7-52, 2016.

Disponível em:

<http://revistas.fflch.usp.br/papia/articl e/view/2571/pdf $>$. Acesso em: $20 \mathrm{dez}$. 2018.

BAGNO, Marcos. O português não procede do latim. Uma proposta de classificação das línguas derivadas do galego. Grial, nº 191, p. 34-39, 2011.

BARREIRO FERNÁNDEZ, Xosé

Ramón. Historia política. In:

BARREIRO FERNÁNDEZ, Xosé

Ramón. et al. Los Gallegos. Madrid: Istmo, 1976. p. 95-148.
BECKER, Lidia. Estandarización onímica en el proceso de elaboración de idiomas romances regionales. In: Els noms en la vida quotidiana. Actes del XXIV Congrés Internacional d'ICOS sobre Ciències Onomàstiques. Annex. Secció 11. Barcelona: Generalitat de Catalunya, 2014. p. 2453-2464. Disponível em: http://www.gencat.cat/llengua/BTPL/ ICOS2011/238.pdf. Acesso em: 20 dez. 2018.

BEIRAS, Xosé Manuel. $\mathrm{O}$ atraso económico de Galicia. Vigo: Galaxia, 1972.

BENNASSAR, Bartolomé; MARIN, Richard. História do Brasil. Lisboa: Teorema, 2000.

BOULLÓN AGRELO, Ana Isabel.

Toponimia galega. Estado da cuestión. In: GORDÓN PERAL, María Dolores.

Toponimia de España. Estado actual y perspectivas de la investigación. Berlín: De Gruyter, 2010. p. 31-57. CABEZA QUILES, Fernando. Toponimia de Galicia. Vigo: Galaxia, 2008.

CARVALHINHOS, Patrícia de Jesus. Estudos de Onomástica em língua portuguesa no Brasil: perspectivas para inserção mundial. In: Simpósio Mundial de Estudos de Língua Portuguesa. São Paulo: FFLCH/USP, 2008. Disponível em:

http://simelp.fflch.usp.br/sites/simelp.ff 
lch.usp.br/files/inline-files/S1401.pdf.

Acesso em: 20 dez. 2018.

\section{CATASTRO DE ENSENADA.}

Madrid: Ministerio de Cultura y Deporte.

Disponível em:

http://pares.mcu.es/Catastro/servlets/S ervletController. Acesso em: 30 nov. 2018.

CUNHA, Manuela Carneiro da. Índios no Brasil. História, direitos e cidadania. São Paulo: Claro Enigma, 2012. Disponível em: https://www.companhiadasletras.com. br/trechos/35025.pdf. Acesso em: 20 dez. 2018.

DIVISÃO REGIONAL DO BRASIL EM REGIÕES GEOGRÁFICAS IMEDIATAS E REGIÕOES GEOGRÁFICAS INTERMEDIÁRIAS 2017. Rio de Janeiro: IBGE, 2017. Disponível em: https://biblioteca.ibge.gov.br/visualiza cao/livros/liv100600.pdf. Acesso em: 4 dez. 2018.

DOVAL IGLESIAS, Lucía; HERMO GONZÁLEZ, Gonzalo. A castelanización da toponimia na documentación instrumental galega da Idade Media. In: MARIÑO PAZ, Ramón; VARELA BARREIRO, Xavier (Ed.). A lingua galega no solpor medieval. Santiago de Compostela: Consello da Cultura Galega, 2016. p. 179-194.

Disponível em:

http://consellodacultura.gal/publicacio n.php?id=4288. Acesso em: 22 dez. 2018. EIRAS ROEL, Antonio. La emigración gallega a América. Panorama general. In:
EIRAS ROEL, Antonio (Ed.). La emigración española a Ultramar, 1492-1914. Madrid: Asociación Española de Historia Moderna, 1991. p. 17-39. Disponível em: http://digital.csic.es/bitstream/10261/7 6346/1/R.C.AEHM_Madrid_1989_1 p.017-039_Eiras_Roel.pdf. Acesso em: 21 dez. 2018.

FAUSTO, Carlos. Os Índios antes do Brasil. Rio de Janeiro: Zahar, 2010. Disponível em: http://professorruas.yolasite.com/resources/fausto, $\% 2$ 0carlos. $\% 20$ os $\% 20$ indios $\% 20$ antes $\% 2$ 0do\%20brasil_.pdf>. Acesso em: $21 \mathrm{dez}$. 2018.

FEYJÓO Y MONTENEGRO, Fr. Benito Gerónimo. Teatro Crítico Universal. Tomo primero. Pamplona: Benito Cosculluela, 1785. Disponível em: http://www.galiciana.bibliotecadegali cia.xunta.es/gl/consulta/registro.cmd?i d=9006>. Acesso em: 22 dez. 2018.

FERREIRO, Manuel. Gramática histórica galega. I: Fonética e morfosintaxe. Santiago de Compostela: Laiovento, 1999.

GARCIA, Elisa Frühauf. O projeto pombalino de imposição da língua portuguesa aos índios e a sua aplicação na América meridional. Tempo [online], v. 12, nº 23, p. 23-38, 2007. Disponível em http://www.scielo.br/pdf/tem/v12n23/ v12n23a03.pdf. Acesso em: $11 \mathrm{dez}$. 2018.

GONZÁLEZ LOPO, Domingo Luís. La emigración gallega a América durante los siglos XVII-XX. Los lugares de destino y 
sus precedentes peninsulares. In: SUÁREZ ALBÁN, Maria del Rosario. Língua e imigração galegas na América Latina. Salvador: Celga, 1998. p. 169-194.

Disponível em:

$<$ http://www.usc.es/catedras/migracs/p ublicaciones/coordinadores/america/a merica.pdf>. Acesso em: 21 dec. 2018. GROSFOGUEL, Ramon. The multiple Faces of the Galician Migration Experience. In: DEPALMA, Renée; PÉREZ-CARAMÉS, Antía (Ed.). Galician Migrations: A Case Study of Emerging Super-diversity, v. 3. Cham: Springer, 2018. p. v-viii. IBGE = Instituto Brasileiro de Geografia e Estatística. Rio de Janeiro: Governo do Brasil. Disponível em: https://www.ibge.gov.br/. Acesso em: 11 dez. 2018.

LACERDA, Marina Basso. Colonização dos corpos: Ensaio sobre o público e o privado. Patriarcalismo, patrimonialismo, personalismo e violência contra as mulheres na formação do Brasil. Tese (Programa de Pós-Graduação em Direito), PUC-Rio, Rio de Janeiro, 2010. Disponível em:

https://www.maxwell.vrac.pucrio.br/Busca_etds.php?strSecao=resulta do\&nrSeq=16570@1. Acesso em: 23 dez. 2018.

LIMA, Emanoela Cristina. A toponímia africana em Minas Gerais. Dissertação (Mestrado em Estudos Linguísticos). Programa de Pos-Graduação em Estudos Linguísticos, Faculdade de Letras, Universidade Federal de Minas Gerais, Belo Horizonte, 2012. Disponível em: http://www.bibliotecadigital.ufmg.br/
dspace/bitstream/handle/1843/LETR96LNKL/a_topon_mia_africana_em_ minas_gerais_emanoela_lima.pdf?se quence=1. Acesso em: $21 \mathrm{dez} .2018$. MARIÑO PAZ, Ramón. Historia da lingua galega. Santiago de Compostela: Sotelo Blanco, 1998.

MELO, Pedro Antonio Gomes de.

Toponímia indígena: um estudo lexical dos nomes de municípios alagoanos de étimo tupi. Veredas Favip, v. 6, no 1, p. 160-179, 2013. Disponível em: http://veredas.favip.edu.br/ojs/index.p hp/veredas1/article/view/51/157. Acesso em: 22 dez. 2018.

MONTEAGUDO, Henrique; LAGARES, Xoán Carlos. Norma e autoridade linguística no galego e no português brasileiro. LaborHistórico, v. 3, n ${ }^{\mathrm{o}}$ 2, p. 12-27, 2017. Disponível em: https://revistas.ufrj.br/index.php/lh/arti cle/view/17123/10424. Acesso em: 21 dez. 2018.

MORENO CABRERA, Juan Carlos. Multilingüismo y lenguas en contacto. Madrid: Síntesis, 2016.

NOLL, Volker; DIETRICH, Wolf. O papel do tupi na formação do português brasileiro. In: NOLL, Volker; DIETRICH, Wolf. O português e o tupi no Brasil. São Paulo: Editora Contexto, 2010. p. 81-103. Disponível em:

https://edisciplinas.usp.br/pluginfile.ph p/314977/mod_resource/content/1/O \%20papel\%20do\%20tupi\%20na\%20f orma $\% \mathrm{C} 3 \% \mathrm{~A} 7 \% \mathrm{C} 3 \% \mathrm{~A} 3 \mathrm{o} \% 20 \mathrm{do} \% 20$ 
portugu $\% \mathrm{C} 3 \%$ AAs $\% 20$ brasileiro.

Acesso em: 20 dez. 2018.

NOMENCLÁTOR. Santiago de

Compostela: Xunta de Galicia. Disponível em

https://www.xunta.gal/nomenclator?.

Acesso em: 30 nov. 2018.

PIEL, Joseph M. Considerações gerais sobre toponímia e antroponímia galegas.

Verba, no 6, p. 5-11, 1979.

PIMENTEL, Patrícia de Cássia Gomes. A toponímia da região central de Minas Gerais. Caletroscópio, v. 4, $\mathrm{n}^{\circ}$ Especial, p. 614-623. Disponível em:

https://www.caletroscopio.ufop.br/ind ex.php/caletroscopio/article/view/160/ 107. Acesso em: 13 dez. 2018.

REAL ACADEMIA ESPAÑOLA.

Diccionario Panhispánico de dudas. Madrid: Santillana, 2005. Disponível em: http://www.rae.es/diccionariopanhispanico-de-dudas. Acesso em: 22 dez. 2018.

RIBEIRO, Darcy. O povo brasileiro. A formação e o sentido do Brasil. São Paulo: Companhia das Letras, 1995. Disponível em:

http://www.afoiceeomartelo.com.br/p osfsa/autores/Ribeiro,\%20Darcy/Darc y\%20Ribeiro\%20\%20O\%20POVO\%20BRASILEIRO. pdf. Acesso em: $21 \mathrm{dez} .2018$.

RODRIGUES, Aryon. As línguas gerais sul-americanas. Papia, v. 4, no 2, p. 6-18, 1996. Disponível em: http://etnolinguistica.wdfiles.com/loca 1--files/artigo\%3Arodrigues- 1996/rodrigues_1996_linguas_gerais.p df. Acesso em: 21 dez. 2018.

RODRIGUES, Aryon. Tupi, tupinamba, línguas gerais e português do Brasil. In: NOLL, Volker; DIETRICH, Wolf. O português e o tupi no Brasil. São Paulo: Editora Contexto, 2010. p. 27-47.

RODRÍGUEZ, Francisco. La lengua. In: BARREIRO FERNÁNDEZ, Xosé Ramón . Los Gallegos. Madrid: Istmo, 1976. p. 219-240.

SANTAMARINA, Antón. A recuperación e salvagarda da toponimia galega. In: Actas do IV Encontros para a normalización lingüística. 9 e 10 de novembro de 2000. Santiago de Compostela: Consello da Cultura Galega, 2002. p. 253-262. Disponível em: http://consellodacultura.gal/mediateca/ extras/CCG_2002_Actas-dos-IV-

Encontros-pola-NormalizacionLinguistica-9-e-10-de-novembro-de2000.pdf. Acesso em: 21 dez 2018.

SANTAMARINA, Antón. Efectos do contacto lingüístico na toponimia galega. In: KREMER, Dieter. Homenagem a Joseph M. Piel por ocasião do seu $85^{\circ}$. aniversário. Tübingen: Max Niemeyer, 1988. p. 87-96.

SANTOS, Joviano Gonçalves dos. O nome e o lugar: A toponímia na região central de Minas Gerais. Tese (Programa de Pos-Graduação em Estudos Linguísticos), Faculdade de Letras, Universidade Federal de Minas Gerais, Belo Horizonte, 2012. Disponível em: http://www.bibliotecadigital.ufmg.br/ dspace/bitstream/handle/1843/LETR- 
95PNBJ/santos_joviano_g..pdf?sequen

ce $=1$. Acesso em: $1 \mathrm{dez} .2018$.

SANTOS, Luiz Eduardo Neves dos.

Toponímia, poder e identidade: uma

abordagem acerca dos logradouros

centrais em São Luís, Maranhão. Geo

UERJ, nº 28, p. 171-195, 2016.

Disponível em: https://www.e-

publicacoes.uerj.br/index.php/geouerj/

article/view/18873/16431. Acesso em:

21 dez. 2018.

SEABRA, Maria Cândida Trindade Costa de. A formação e a fixação da Língua

Portuguesa em Minas Gerais: a

Toponímia da Região do Carmo. Tese

(Programa de Pos-Graduação em Estudos

Linguísticos), Faculdade de Letras,

Universidade Federal de Minas Gerais,

Belo Horizonte, 2004. Disponível em:

http://www.bibliotecadigital.ufmg.br/

dspace/handle/1843/ALDR-64KQ9A.

Acesso em: $22 \mathrm{dez} .2018$.

SEEMANN, Jörn. A toponímia como construção histórico-cultural: o exemplo dos municípios do estado do Ceará.

Vivência, $n^{\circ}$ 29, p. 207-224, 2005.

Disponível em:

https://www.academia.edu/647642/A

TOPON\%C3\%8DMIA_COMO_C

ONSTRU\%C3\%87\%C3\%83O_HIS

T\%C3\%93RICO-

CULTURAL_o_exemplo_dos_munic \%C3\%ADpios_do_estado_do_Cear $\%$

C3\%A1. Acesso em: 22 dez. 2018.

SILVA, Érica Sarmiento da. Rumbo aos

trópicos: a emigración galega a Brasil. In:

CAGIAO VILA, Pilar (Coord.). A

emigración galega a América do Sur.
A Coruña: Hércules de Ediciones, 2013.

p. 199-236.

SIQUEIRA, Kênia Mara de Freitas;

DAVID, Nismária Alves. Topônimos de origem indígena: $\mathrm{O}$ papel do tupi na nomeação dos lugares goianos.

Fronteiras: Journal of Social, Technological and Environmental

Science, v. 3, nº 1, p. 119-131, 2014.

Disponível em:

http://periodicos.unievangelica.edu.br/ index.php/fronteiras/article/view/788/

770. Acesso em: 22 dez. 2018.

STESSUK, Sílvio. A implantação da língua portuguesa no Brasil, em contato com o Tupí Antigo e as Línguas Africanas. Todas as Letras, v. $8, \mathrm{n}^{\mathrm{o}} 1, \mathrm{p}$. 96-102, 2006. Disponível em: http://tupi.fflch.usp.br/sites/tupi.fflch.u sp.br/files/a\%20implanta $\%$ C3\%A7\%C 3\%A3o\%20da\%201\%C3\%ADngua\% 20portuguesa $\% 20$ no\%20Brasil.pdf. Acesso em: 16 dez. 2018.

VELASCO, Denise de Oliveira Barbosa; TAVARES, Marilze. A presença e a motivação de topônimos indígenas nas ruas de Dourados/MS. Arredia, v. 5, no 9, p. 15-34, 2016. Disponível em: http://ojs.ufgd.edu.br/index.php/arredi a/article/viewFile/5617/3018. Acesso em: 21 dez. 2018.

VIDAL FONSECA, Guillermo. La antroponimia de la comarca de Barcala (Galicia): evolución histórica moderna y causas implicadas. Estudios Interlingüísticos, n 4, p. 99-117, 2016. VILA DE PRADO, Roberto. El genocidio/epistemicidio contra los 
africanos con la trata y la esclavitud en Hispanoamérica. Analéctica, $n^{\circ} 22$, p. 1 10, 2017. Disponível em: http://www.analectica.org/articulos/vi la-genocidio/?pdf=986. Acesso em: 22 fev. 2019. 